\title{
Mindsets Set in Concrete? Exploring the Perspectives of Domestic Travellers on New Zealand's (Auto-)Mobility Culture
}

\author{
Maria Juschten ${ }^{1, *(D)}$, Shannon Page ${ }^{2}$ and Helen Fitt ${ }^{3}(\mathbb{D}$ \\ 1 Institute for Transport Studies, University of Natural Resources and Applied Life Sciences Vienna (BOKU), \\ Peter Jordan Straße 82, 1190 Vienna, Austria \\ 2 Department of Environmental Management, Faculty of Environment, Society and Design, Lincoln \\ University, Ellesmere Junction Road/Springs Road, Lincoln 7647, New Zealand; Shannon.Page@lincoln.ac.nz \\ 3 Centre of Excellence: Sustainable Tourism for Regions, Landscapes and Communities, Lincoln University, \\ Ellesmere Junction Road/Springs Road, Lincoln 7647, New Zealand; Helen.Fitt@lincoln.ac.nz \\ * Correspondence: maria.juschten@boku.ac.at; Tel.: +43-1-47654-85623
}

Received: 8 August 2020; Accepted: 11 September 2020; Published: 16 September 2020

\begin{abstract}
Tourism trips in New Zealand are strongly car-dominated. Research suggests that such car use practices do not only emerge from purely rational economic considerations but also result from symbolic and affective motives, institutionalized mobility cultures, and habitualized mobility practices that have developed and materialized in spatial structures over decades. This paper explores the notion of automobility and its influence on the domestic tourism mobilities of Christchurch residents. It does so by applying $Q$ methodology, an inherently mixed method that involves participants structuring statements by their level of agreement, followed by a range of qualitative post-sorting questions. The statements draw on insights from the study of tourism mobilities, mobility cultures and classical mode choice research, allowing this study to provide novel insights into the under-researched field of urban-rural tourism mobility. The juxtaposition of quantitative $Q$ and the qualitative interview results reveals influential factors at the personal, interpersonal, societal/political and infrastructural level. The results then feed into a conceptualisation of influential factors of tourism mobility choices using an embedded, interlinked structure that captures the dynamics of social interactions (i.e., feedback-loops). Policy implications are discussed with regards to possible sustainability pathways in line with New Zealand's decarbonisation strategy.
\end{abstract}

Keywords: mobility culture; rural leisure trips; New Zealand; sustainable tourism mobility; exploratory analysis; Q methodology

\section{Introduction}

New Zealand is a country that is well-known for its vast natural landscapes, breath-taking sceneries and a unique diversity in flora and fauna, and its tourism marketing has focused on these landscapes and natural features since the very beginning of tourism in the late 19th century [1]. While most research focuses on international visitors, the large share of domestic guest nights $(57.4 \%$ of the 40.4 million guest nights counted in the year ending in June 2019) were experienced by domestic travellers (see [1]). This justifies further research on domestic tourism, with its large economic and social significance for New Zealand. Especially during times of exogenous shocks (such as the economic crisis or the recent global pandemic), New Zealand's economy largely depends on domestic tourists, increasing the importance of research on its motivators, facilitators and structures [2].

Inspired by the diversity and spatial proximity of natural and cultural sights, New Zealand's tourism is largely mobility-based (rather than resort-based tourism, such as in the Maldives, for example). 
In consequence, domestic tourism or leisure trips (defined as trips above $40 \mathrm{~km}$ outside the travellers' place of residence, see [1]) towards rural destinations are strongly dominated by car travel. Between $81 \%$ and $94 \%$ of domestic leisure trips are taken by car [3], according to our own analysis using New Zealand's Household Travel Survey data from 2003-2014.

New Zealand's second largest city and the tourist source market investigated in this study, Christchurch, has undergone various efforts in the past years to promote cycling and public transport (PT) usage. Many of these initiatives have been part of the rebuilding processes after the 2010/11 earthquakes hit this city of 340,000 inhabitants characterized by a polycentric urban structure and low urban density. Nevertheless, Christchurch is still largely car-dominated in terms of people's minds, the materialized urban structures [4] and the trips being made; e.g., $84 \%$ of Christchurch's commuting trips are made by car, see [5]. Automobile dependency is even stronger in the rural areas that many of New Zealand's tourist attractions are located in. As such, self-drive tourism either by car or van is the most prominent way of travelling in New Zealand [6], and is a substantial contributor to regional economies along classical tourist routes in many parts of New Zealand.

Research suggests that people's practices of car usage- -both in the context of daily trips and tourism-do not only emerge from purely rational economic considerations but are also a product of aesthetic, sensory and affective motives, as well as institutionalized mobility cultures that have developed over decades [7-9]. As a global phenomenon, car ownership and usage is associated with core features expected from development and modernity, namely freedom, individualisation, convenience and comfort [10]. As such, the role of the automotive industry exceeds beyond jobs and GDP contributions; it has turned into a "technological regime dominating the economies of several industrialized countries" [11] and, in consequence, shapes public and political discourses. Despite there being no uniform global experience of car travel, the various forms of car-focused tourism mobilities prevail in most Western - as well as many developing-countries. They can be conceptualized as automobilities, reflecting "a simultaneous achievement of autonomy and mobility" [12]. This concept strongly revolves around the notions of freedom, sense of control and independence when travelling, all of which have become essential experiential tourism expectations [9]. Wilson and Hannam [12] challenge the often uncritical and rather "dreamy" notion of automobility that disregards the various social, environmental and economic problems associated with extensive car travel. As pointed out by Hannam et al. [9], the study of tourism (auto)mobilities, as framed within the mobilities paradigm, understands travelling as an activity that is strongly bound to people's every-day life and social realities, rather than an isolated event outside the normal, therefore tying the problems arising from tourism automobility into a matter of every-day life choices.

\subsection{Factors Influencing Transport Mode Choices in a Tourism Context}

Increasingly for every-day life choices in cities, but to a lesser extent also for tourism mobility in urban and rural settings, awareness is rising that ever-increasing private and fossil fuel-based car usage creates a wide range of problems, ranging from environmental and health concerns to debates over the just and efficient usage of limited public spaces. Not only to promote the use of existing transport alternatives to the private fossil-based car but also to develop new options in line with travellers' experiential expectations, understanding transport mode choices and underlying narratives matters. In tourism mobility, this need for understanding covers both destination and transport aspects, due to their interconnectedness, with transport having the role of either a facilitator, a constraint or even an inherent goal for any tourism activity [13]. In this sense, the relevance of the results also extends beyond classical policy-making, since tourism mobility also touches upon destination management, cooperation between private and public stakeholders, and transport policy-makers at different spatial levels.

Within the analysis of influential choice factors, much of the existing research in transport is shaped by positivist thinking and practice. Dominated by econometric modelling techniques based on stated or revealed preference-based data, the majority of such empirical research mainly covers quantifiable 
and therefore more rational choice influences, which are possibly even answered by respondents with a bias towards socially-desirable responses [14]. Given the methodological individualism involved in these modelling approaches, most of these studies assume travellers to have full agency to perform whatever choice is most rational (or, at least, beneficial) to them. However, research shows that these underlying assumptions of rationality and full agency don't match reality $[15,16]$. In many cases, personal agency is restricted by external factors. This is especially applicable to tourism decisions, which are often joint decisions with other co-travellers [17], strongly limiting the personal power of decision-making. While people might, for example, consider themselves environmentally conscious, these factors can lead to them still making environmentally harmful tourism choices [18]. Typically, these studies cover some or all of the objective and subjective dimensions (a modified version of the classification by [19] is shown in Table 1 below), and are integrated into empirical studies through a range of indicators of individual tourism mobility choices.

Table 1. Dimensions and influential factors for tourism travel choices partly based on [19].

\begin{tabular}{|c|c|c|}
\hline Choice Dimension & Examples of Choice Influences & Literature \\
\hline \multicolumn{3}{|c|}{ Objective Influence Factors } \\
\hline $\begin{array}{l}\text { (1) sociodemographic features including } \\
\text { available mobility tools }\end{array}$ & age, gender, education, income, car ownership, PT ticket & [19-21] \\
\hline (2) overall trip characteristics & length of stay, budget, travel party, spontaneity of trip booking & {$[19,20,22]$} \\
\hline (3) transport mode attributes & travel time, costs, service quality & [22-25] \\
\hline (4) destination features & tourism and transport infrastructure & {$[20,25,26]$} \\
\hline \multicolumn{3}{|c|}{ Subjective Influence Factors } \\
\hline (5) attitudes, norms, perceptions & $\begin{array}{l}\text { attitudes towards cars and PT and relevant destinations, } \\
\text { risk perceptions }\end{array}$ & {$[21,27,28]$} \\
\hline $\begin{array}{l}\text { (6) travel motivations and related } \\
\text { experiential expectations }\end{array}$ & i.e. relaxing, sports, culture, expectation of privacy, adventure & {$[9,29,30]$} \\
\hline
\end{tabular}

Some qualitative studies using alternative methodologies also display a bias towards these utility-maximization narratives, and both their research set-up and resulting data is shaped that way [31]. Especially in empirical studies, only a little focus is given to the cultural meanings of automobility, and the related drivers and barriers to behaviour change [25,32].

\subsection{The Perspectives of Tourism Mobilities Research on the Desired Experiences of Car Travel}

In contrast, research on tourism mobilities has largely focussed on the less rationalized choice factors, and the underlying meanings and experiences tied to different transport modes, especially to the car as the "chief purveyor of autonomous movement" [9]. Hannam et al. [9] also emphasize that transport means can have a considerable influence on the overall tourist experience. As such, the existing research points out the personal benefits of automobility with regards to the freedom, sense of control, flexibility and individuality it provides to travellers by extending their spatiotemporal range. Furthermore, the co-existence of friends or family members in a private, controlled space can turn the car into an extension of one's home, where one is shielded from the expectations, views and disturbances of the outside world. The fact that this private space and the landscapes experienced through different senses can usually be tailored to personal needs in terms of temperatures, music, travel speed and outside views enhances these comforts. Additionally, the research emphasizes the sensations of unpredictability along the road compared to rigid train tracks, offering little moments of surprise in terms of routing and speeds (and if so, they might not be the kind of surprise people are actually seeking) [9]. By enabling access to more secluded sights, they might also transmit a sense of superiority, or at least avoid the feeling of being excluded from worthwhile sights [33].

In this context, Edensor [34] argues that public transport insulates people from truly experiencing the landscapes through which they travel by turning travellers into static observers, as opposed to the sense of adventure tied to the spatiotemporal and mental freedoms that car travellers may experience. 
Butler and Hannam [2] contest this notion by pointing out that PT travel also involves experiential benefits; for example, by enhancing the visual glance of the passing landscapes with the peace of mind to enjoy it without the need to concentrate on the road. Along similar lines, Sheller and Urry [35] emphasize the restrictions of car travels regarding sensual outside experiences, the speeds at which cars usually travel and the blurriness of experiences caused by the driver's need to focus on the road. This last aspect may be especially applicable to New Zealand's South Island, with its many curvy and narrow roads. When adding the distress and frustration that some travellers experience in the face of difficult road or weather conditions or heavy congestion, these studies may offer alternative perspectives on the convenience and comfort often tied to car travels only. In doing so, they represent interesting starting points for discussing the design elements of a sustainable and appealing tourism mobility system in both New Zealand and beyond.

To date, little insights exist on the factors influencing the tourism mobilities of domestic travellers in New Zealand. Vaguely connected studies exist that emphasize the prevalence of automobility in every-day life, which is assumed to transcend into travel patterns for tourism purposes (as the previously listed modal split statistics illustrate). The work by Fitt [4], for example, identifies the stereotypes associated with bus users, as well as the habitus of non-bus use practices (even though adequate routes and schedules might be in place) and general anti-bus dispositions as a main barrier to the use of public transport within Christchurch, even though residents might consider PT use in different geographical contexts. Hopkins and Stephenson [36] argue, however, that despite the existing (infrastructural, political and psychological) path dependencies of New Zealand's car-reliantculture, the share of younger travellers using various transport modes is increasing, which challenges the notion of a car-only country. This view is contested by a study on active travel, which shows that, for rural settings in New Zealand, travel distance plays an exceedingly strong role, leading to the perceived infeasibility of car alternatives [37]. With regards to tourism mobilities, most research in New Zealand is centred on international travellers or particular groups of campervan or cycling tourists (Bell, 2018). While some of these aspects may also apply to domestic travellers, existing car ownership, driving habits, familiarity with the roads and both written und unwritten rules, as well as the beforehand mentioned habitus of not using public transport in every-day life in Christchurch, may further inhibit alternatives to car use for leisure trips.

Regarding their choice of destination, the self-perception of many New Zealanders as being "an outdoor-loving people, with a way of life that is shaped around action and interaction with the environment" [38] can be assumed to affect the mobility practices and needs of domestic travellers. Within the general travel motives (outdoor activities, culture, visiting friends and relatives etc.), Hall and Kearsley [39] observe an increasing importance of individual values, self-fulfilment and achievement, as well as a desire for simplicity that contrasts people's demands for convenience in daily life. While parts of New Zealand's car dominance for leisure trips can be attributed to its spatial patterns, existing transport infrastructure and automobile culture [40], leisure-specific motives can be assumed to also play their part in determining travel needs and shaping expected experiences. However, research on rural tourism in New Zealand is scarce, and different studies highlight the need for a better understanding of the motivations and travel patterns of travellers visiting rural places [39], especially for different types of domestic travellers [3,41].

\subsection{Resulting Research Objectives}

Given these research gaps, this study tries to explore the various influences on the domestic tourism travel behaviour of New Zealanders, and asks: "Which factors frame people's narratives of their tourism-related transport mode choices?" Previous research from quantitative transport science highlights the relevance of instrumental choice motives including costs, time and the reliability of the available services. In contrast, the study of tourism mobilities emphasizes the importance of the emotional and symbolic nature of car use motives, and the role that togetherness, privacy, freedom, a sense of control and experiential expectations may play [9,12]. Research on mobility cultures, defined as 
"specific socio-cultural settings consisting of travel patterns, the built environment, and mobility-related discourses" [31], additionally highlights the role of public norms and discourses—as well as materialized infrastructures and spatial forms-in such decisions. In a rather exploratory manner, this paper aims to combine these various perspectives, and to identify different groups of travellers by their subjective viewpoints regarding travel needs and their experiential expectations related to the trip. Given the semi-exploratory nature of this question and the aim to identify different types of travel narratives, Q Methodology—as the study of subjectivity—seems most suitable [42].

Novel insights were generated by applying Q Methodology as an inherently mixed method to the under-researched study field of the domestic tourism mobilities of Christchurch residents. By building on existing research on tourism mobilities [9,12], mobility cultures [8,31,43], travel motives and transport mode choices $[20,23,32]$, it attempts to strengthen the interrelations and intersections between these research domains. In doing so, the paper provides a more integrated perspective on tourism-related mobility narratives and practices. Influenced by the increasing urgency of action to mitigate climate change, this study will use the findings to discuss possible sustainability pathways in the field of tourism management and transport policies.

\section{Materials and Methods}

Our research question is neither purely quantitative nor qualitative. Furthermore, relevant previous research has been conducted using various methodologies including quantitative surveys, qualitative interviews, group discussions and theoretical considerations on tourism mobilities. To take as many of these previous insights as possible into consideration while at the same time exploring the perceptions of transport options and reflections upon personal choice influences in a structured manner, Q methodology seems suitable [44-46]. It develops an in-depth, yet standardized dataset into a qualitative question, and uses statistical tools and qualitative content analysis to explore the existing viewpoints on the question at hand. $Q$ methodology tries to identify groups of people who share the way they structure a set of items on a given topic, assuming a limited number of distinct viewpoints on any given subject [47]. Unlike classical R methodology, which tries to find relations between people, $\mathrm{Q}$ tries to find relations between statements or topics in order to draft a comprehensive picture of the available discourses in society on a given topic [48]. To identify the full set of viewpoints, sufficient focus needs to be placed on diversity aspects within the statement development and participant selection [49].

Not many studies use $Q$ methodology in the context of transport or tourism choices. Q studies in the field of transport mainly look at attitudes towards transport modes in an urban context $[32,50,51]$ and their relevance for policy-making [52,53] or social inclusion [54,55]. Despite being few, some of these studies provide interesting insights for this study. The research by Cools et al. [32], for example, has aimed at depicting dominant discourses around medium-distance travel decisions. One of the groups is those of 'exclusive motorists', whose strong car preference makes them choose their destinations by car-related accessibility. Given the modal split and existing public debates, this might be the dominant type in New Zealand. In the tourism field, several studies exist using Q methodology as a research method. Their focus primarily lies on either the visitors' destination meanings or images [42,46,56], stakeholder perspectives [57], or the residents' perspectives on how tourism affects their community $[45,56]$. Since this study focuses mainly on transport mode choices concerning leisure trips, different meanings associated with the visited places are secondary for this study.

\subsection{Q Sample-'Concourse' Development}

The Q sample of this study is structured along the different behavioural, infrastructural, political and cultural dimensions of mode choice factors, and applies it to a leisure context to depict the factors influencing tourism-related transport choices. The nature of $Q$ as the study of subjectivity does, however, contradict the holistic integration of both subjective and objective indicators. Therefore, we place the focus of our $Q$ statements on the subjective indicators (categories 5 to 9). For these 
categories, a separate literature search was performed seeking existing $Q$ studies in order to integrate reliable and tested sets of statements. When these were unavailable, the statements were developed based on similar non-Q study research findings [39,58] or distant $Q$ studies [46]. Within the bounds of possibility, some of the other indicators (categories 3 and 4) were re-phrased as perceptive statements; others were left out intentionally. Table 2 illustrates the data collected throughout the study.

Table 2. Data collection within the $Q$ study.

\begin{tabular}{|c|c|c|c|c|c|}
\hline No. & Category (CAT) & Elements Included in the Study & Study Part ${ }^{a}$ & Statements & Relevant Literature \\
\hline 1 & Sociodemographics & $\begin{array}{l}\text { Gender, age, education, occupation, } \\
\text { family size }\end{array}$ & S & / & \multirow{4}{*}{ Information from $[8,58]$} \\
\hline 2 & Urban form indicators & Residential location & $\mathrm{S}$ & 1 & \\
\hline 3 & $\begin{array}{l}\text { Transport and tourism } \\
\text { infrastructure and supply }\end{array}$ & $\begin{array}{l}\text { Satisfaction with and importance of } \\
\text { infrastructure }\end{array}$ & Q & 5 & \\
\hline 4 & Travel Behaviour & Car ownership, mode choice & $S, Q$ & 5 & \\
\hline 5 & Transport policy & Need for political action & Q & 4 & \multirow{2}{*}{$\begin{array}{c}\text { Adapted loosely from } \\
{[8,32,52,55]}\end{array}$} \\
\hline 6 & Public discourses & $\begin{array}{l}\text { Problem awareness, i.e., } \\
\text { environmental issues }\end{array}$ & Q & 6 & \\
\hline 7 & Instrumental car use motives & i.e., time, costs, convenience & Q & 7 & \multirow{3}{*}{ Adapted from $[32,51]$} \\
\hline 8 & $\begin{array}{l}\text { Symbolic-affective car } \\
\text { use motives }\end{array}$ & i.e., status, freedom, fun, norms & Q & 6 & \\
\hline 9 & Additional trip aspects & i.e., repetition of journeys & Q & 5 & \\
\hline 10 & $\begin{array}{l}\text { Preferred type of leisure activity } \\
\text { during trip }\end{array}$ & $\begin{array}{l}\text { Tramping/walking, fishing, } \\
\text { camping, water sports etc. }\end{array}$ & $\mathrm{S}$ & / & \\
\hline 11 & Chosen destination & Memory related to trip & S, I & 1 & Adapted from [56] \\
\hline 12 & Motivation for leisure trip & $\begin{array}{l}\text { Relaxation, nature, family time, } \\
\text { local culture etc. }\end{array}$ & Q & 9 & Adapted loosely from $[39,46]$ \\
\hline
\end{tabular}

To test the comprehensiveness and intelligibility of both the statements and the introduction, questionnaire, and post-sorting questions, four pilot studies were conducted with researchers from tourism (2) and transport (1), and with former $Q$ experience (1). The pre-test provided valuable feedback on useful changes with regards to the intelligibility of the statements and the ease of use of the material (laminated cards, scale labelling etc.). However, future studies may also consider performing pre-tests with lay people to include their needs and preferences in the design of the material.

\subsection{P-Set-Study Participants}

The literature suggests that, in $\mathrm{Q}$ methodology, the diversity of the participants is more important than the number of participants [55,59], and studies have provided relevant results with as few as 17 participants [60]. Some research suggests that the number of statements should be around double the number of participants $[45,59]$. To ensure this diversity of viewpoints, a structured participant sampling approach was applied using the following criteria: (a) Christchurch residents above the age of 18 with (b) an interest in one or more outdoor leisure activities (e.g., tramping, mountain biking, fishing, boating) and (c) vehicle ownerships (i.e., SUV, EV). Christchurch was chosen as a case study because it is the largest city in the South Island, and thereby represents one of the largest source markets for domestic tourism. The recruitment of the 25 participants took place through personal contacts and their suggestions (snowballing system), as well as social media groups related to different leisure activities.

All of the study participants live in the Greater Christchurch area, and therefore live in the context of a low density city with high levels of car ownership and use [5]. Public transport provision in Christchurch primarily consists of bus use (there is no urban rail provision, and one small public ferry service to an outlying settlement). Bus use amounted to $2 \%$ of daily travel in the city in 2018 [61]. The research's focus on outdoor leisure pursuits (such as tramping and boating) suggests that regional travel conditions may be more important to the study objectives than travel options within Christchurch itself. Christchurch is linked to national rail and bus services, but these are very limited in terms of the destinations that can be reached and the frequency of the services. From Christchurch, it is possible 
to drive to any other road-accessible settlement in the South Island of New Zealand within a day, with Bluff (to the South), Nelson (to the North), and Greymouth (to the West) all accessible in (usually) less than $8 \mathrm{~h}$.

\subsection{Q Sorting-Interview Procedure}

All of the interviews were conducted in New Zealand's peak domestic travel season, between December 2019 and January 2020. The interviews started with a short welcome, followed by the questionnaire completion and an introduction to $\mathrm{Q}$ methodology. After that, the participants were asked to describe a memorable domestic summer leisure trip to provide them with a tangible picture in mind, as described by [56]. They were then handed the 47 statement cards and were asked to sort them into piles of agreement, disagreement and neutral, followed by the fine sorting on the bell-shaped Q-sorting board (see Figure 1). Upon the completion of the sorting, a semi-structured post-sorting interview (in average $20 \mathrm{~min}$ ) was performed. The questions covered: (1) the reasoning behind their placement decisions (with a focus on the extreme ends of the $Q$ board) and respective follow-up questions, (2) missing statements, (3) possible statement contradictions, and (4) their views on electric vehicles (EVs) and public transport (PT) as alternative tourism mobility options.

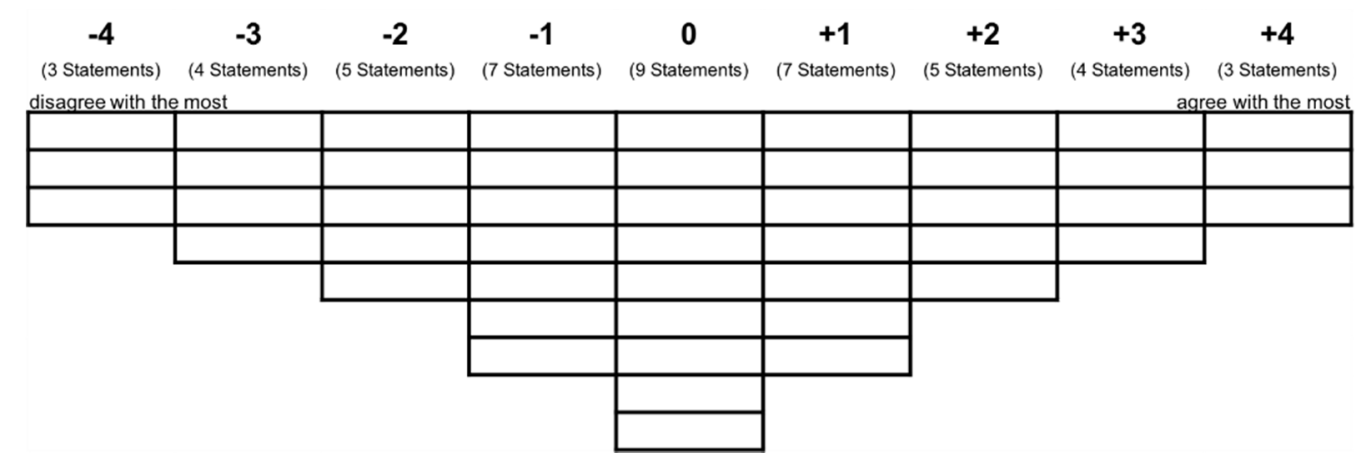

Figure 1. Model of the Q-sorting board.

\subsection{Analysis of the $Q$ Methodology and Interview Data}

The data were analysed using Ken-Q Analysis Version 1.0.6, a web-based analysis tool. It applies a by-person (instead of a by-variable) factor analysis to retrieve themes shared by different groups of participants [59,62]. The first step is a Pearson's correlation of all of the entered Q-sorts [62] with each other, followed by a Principal Component Analysis applied to all 25 Q-sorts. The selection of factors to be kept for factor rotation followed both statistical and theoretical considerations $[59,62]$. We considered the eigenvalue of all of the factors (seven factors had an eigenvalue above one); the number of significantly loading Q-sorts per factor (four factors had at least two Q-sorts significantly loading on each factor), the shape of the scree plot (suggesting a three- or four-factor solution), as well as the theoretical significance of resulting factors. Ultimately, four factors were kept for the Varimax rotation. Afterwards, the factor matrix was generated, which illustrates how strongly each participant matches the viewpoints covered by each factor. To determine the significant $Q$-sorts for each factor, Q-sorts with loadings above $2.58 \times(1 / \sqrt{ } \mathrm{N})( \pm 0.38)$ were considered significant at the 0.01 level [47]. To increase the statistical scrutiny and minimise the number of sorts to be excluded, the significance threshold was raised to \pm 0.50 [55]. In the last step, the factor scores were computed, which show how strongly each statement scores on each of the factors (see Appendix A Table A1). The rough transcripts of the post-sorting interviews were analysed thematically, and the data were coded using categories that relate to the key insights of the statistical factor description, in order to be able to contrast both parts of the findings. 


\section{Quantitative Q Study Results}

The results of this study stem from $25 \mathrm{Q}$-sorting interviews which were conducted with 13 female and 12 male participants between the age of 22 and 74 (average age: 42.5, median age: 39). Among the participants, five were students, 16 were employed, two were self-employed and two were retired. Eight participants lived in one of the inner suburbs, ten in one of the outer suburbs and seven in one of Christchurch's satellite towns. On average, the participants' households owned 1.03 cars per adult in the household ( 0.84 vehicles for the entire household). With regards to the memorable trips to predominantly rural, nature-based destinations, a number of different destinations throughout New Zealand were mentioned. They are visualized in Figure 2, below.

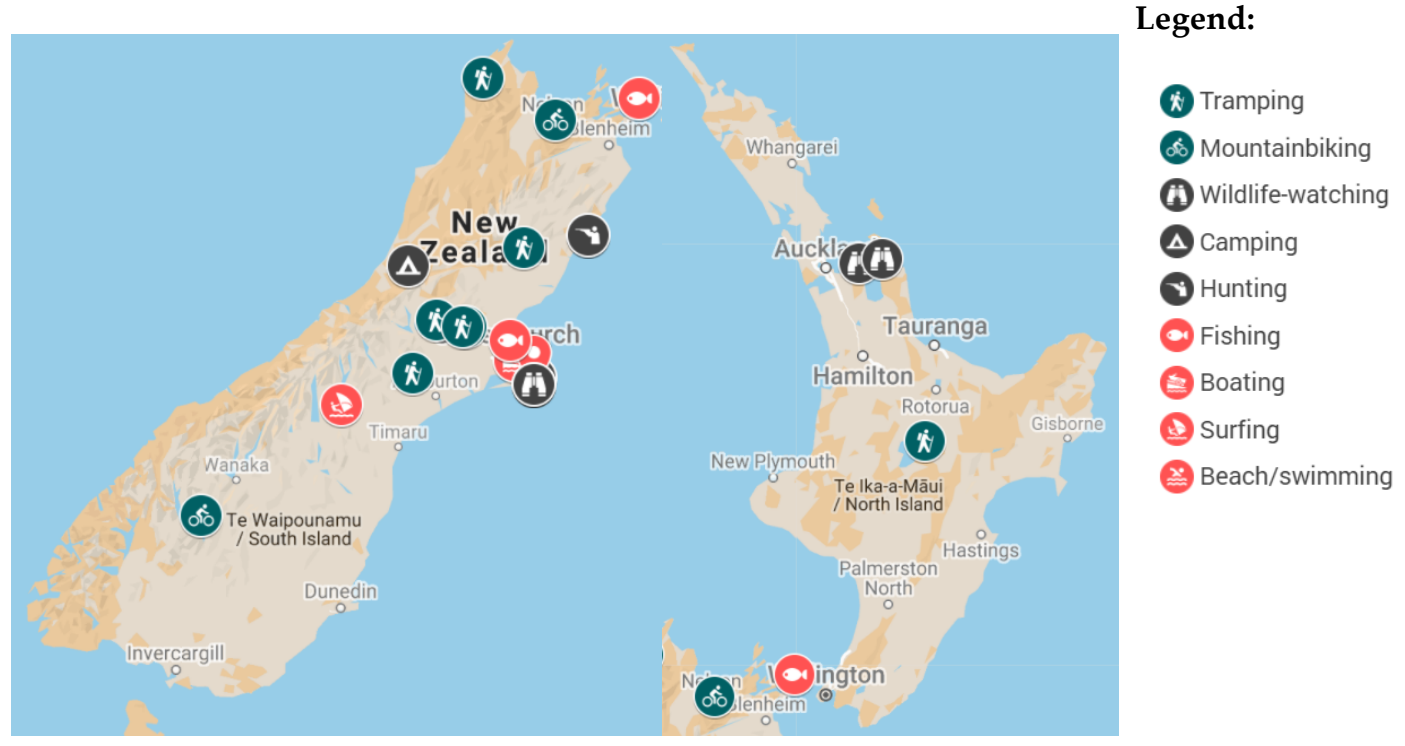

Figure 2. Memorable trips participants had in mind when sorting the $\mathrm{Q}$ statements and activities performed there (Left: South Island; Right: North Island). Map created using Google MyMaps.

The inverted factor analysis performed within the $Q$ methodology reveals four distinct perspectives concerning the conceptions of or perspectives of Christchurch residents on their individual tourism mobility when travelling in New Zealand. These four groups are: (1) convenience-driven car proponents, (2) PT-affectionate multi-modal travellers, (3) EV-and PT-positive car dependents, and (4) those who are car-attached for stress avoidance. This four-factor solution accounts for $56 \%$ of the variance within the data. Table 3, below, shows the factor matrix of all of the participants, supplemented by personal and household characteristics. In total, 23 participants loaded significantly on one of the retrieved factors or viewpoints (indicated by an ' $X$ ' in the factor matrix), thereby exemplifying what this factor stands for [59]. None of the Q-sorts were confounded, but two Q-sorts did not load significantly on any factor. The reliability (and strength) of the final factor solution is commonly judged by the composite reliability, which increases with the number of defining Q-sorts, and will ideally be above 0.95 , see [53]. The correlation values between the factors show that Factors 1 and 4 are fairly similar (0.55), and that Factors 2 and 3 share some similarities (0.42). This follows the line of argumentation of Britton [63], according to whom "the dynamics of tourism can only be fully understood with reference to its wider societal contexts". Consequently, individual choices must be observed with consideration of their broader societal framing. 
Table 3. Rotated four-factor matrix with participant characteristics; ' $X$ ' indicates a defining exemplar.

\begin{tabular}{|c|c|c|c|c|c|c|c|c|}
\hline \multirow{2}{*}{ Nr. } & \multicolumn{4}{|c|}{ Personal Characteristics } & \multicolumn{4}{|c|}{ Factor Scores $(>0.38)$} \\
\hline & Sex, Age & Used Vehicles and Nr. of Cars Per Adult in $\mathrm{HH}^{\mathrm{a}}$ & HH Size ${ }^{b}$ & HH Location & 1 & 2 & 3 & 4 \\
\hline P17 & Female, 39 & $4 \mathrm{WD}, \mathrm{EV}(1)$ & $2+2$ & outer & $0.726 \mathrm{X}$ & & & \\
\hline P23 & Female, 30 & SUV (0.5) & $2+0$ & outer & $0.683 X$ & & & \\
\hline P19 & Female, 34 & CC (2) & $1+1$ & outer & $0.681 X$ & & & \\
\hline P07 & Male, 65 & $4 \mathrm{WD}(0.67)$ & $3+0$ & outer & $0.651 X$ & & & \\
\hline P01 & Female, 71 & $\mathrm{CV}, 4 \mathrm{WD}(3)$ & $2+0$ & inner & $0.644 \mathrm{X}$ & & & \\
\hline P18 & Male, 35 & CC (2) & $3+0$ & inner & $0.627 X$ & & & \\
\hline P09 & Male, 59 & SUV, CV (0.67) & $3+0$ & satellite & $0.512 X$ & & 0.436 & \\
\hline P24 & Female, 23 & NoC $(0)$ & $1+0$ & outer & & $0.766 \mathrm{X}$ & & \\
\hline P25 & Female, 74 & CC (1.5) & $2+0$ & outer & & $0.710 \mathrm{X}$ & & \\
\hline P04 & Female, 60 & NoC (0) & $3+0$ & satellite & & $0.696 \mathrm{X}$ & & \\
\hline P21 & Male, 36 & CC (1) & $2+2$ & inner & & $0.637 \mathrm{X}$ & & \\
\hline P06 & Male, 48 & NoC (0) & $2+2$ & inner & -0.427 & $0.548 \mathrm{X}$ & 0.485 & \\
\hline P08 & Female, 34 & $\mathrm{NoC},(\mathrm{CC})(0.5)$ & $2+0$ & inner & & $0.532 X$ & & 0.383 \\
\hline P11 & Male, 39 & EV, 4WD (1) & $2+1$ & inner & & & $0.784 X$ & \\
\hline P14 & Male, 39 & CV (0.5) & $2+0$ & inner & & & $0.665 X$ & \\
\hline P22 & Male, 24 & $4 \mathrm{WD}(1.33)$ & $3+0$ & satellite & & & $0.648 \mathrm{X}$ & \\
\hline P20 & Male, 36 & $4 W D(1)$ & $2+0$ & outer & & & $0.617 X$ & \\
\hline P10 & Female, 47 & SUV, CV (0.67) & $3+0$ & satellite & & 0.405 & $0.557 X$ & \\
\hline P03 & Female, 45 & CV, EV (2) & $2+2$ & satellite & & & & $0.734 X$ \\
\hline P05 & Male, 36 & CC (1) & $2+0$ & outer & & & & $0.633 X$ \\
\hline $\mathrm{P} 13$ & Female, 49 & SUV, 4WD (1.5) & $2+2$ & satellite & 0.436 & & & $0.607 X$ \\
\hline P12 & Female, 23 & CC (1) & $3+0$ & satellite & & & & $0.567 X$ \\
\hline P16 & Male, 42 & 4WD, EV (1) & $2+2$ & outer & 0.478 & & & $0.500 \mathrm{X}$ \\
\hline P15 & Male, 34 & SUV, CC (1) & $2+0$ & outer & 0.448 & & & 0.409 \\
\hline \multirow[t]{10}{*}{ P02 } & Female, 43 & 4WD, EV (1) & $2+1$ & inner & & & & \\
\hline & & Eigenvalues & & & 6.41 & 3.56 & 2.35 & 1.59 \\
\hline & & $\%$ Explained variance & & & 18 & 13 & 14 & 11 \\
\hline & & $\%$ Cumulative explained variance & & & 18 & 31 & 45 & 56 \\
\hline & & Number of defining Q-sorts & & & 7 & 6 & 5 & 5 \\
\hline & & Composite reliability & & & 0.966 & 0.96 & 0.952 & 0.952 \\
\hline & & Standard error of factor scores & & & 0.184 & 0.2 & 0.219 & 0.219 \\
\hline & & & & & 1 & 0.31 & 0.35 & 0.55 \\
\hline & & Factor Correlation & & & 2 & - & 0.42 & 0.13 \\
\hline & & & & & 3 & - & - & 0.16 \\
\hline
\end{tabular}

${ }^{\mathrm{a}} \mathrm{NoC}=$ no car, $\mathrm{CC}=$ conventional car, $\mathrm{EV}=$ electric vehicle, $4 \mathrm{WD}=4$-Wheel-Drive, $\mathrm{CV}=$ Campervan, ${ }^{\mathrm{b}}$ Household (HH) size: adults + children.

Overall, the four factors share their desire for nature experiences, preferably in remote places, rather than city or cultural holidays. The importance of freedom and independence is another aspect ranked highly by all but one group. The frustration with car-dependency and the resulting need of a different transport system were unanimously placed in less decisive positions. Part of the reason might be that some participants generally consider PT to be a useful option, but not in rural places, leading to ambivalent feelings about this PT-related statement. This is also illustrated by the disinterest of participants in using car alternatives in the destinations themselves. On the other hand, there is a consensus that investments in car infrastructure and improved accessibility aren't desirable, often justified by people's interest in keeping remote places remote. The four factors are described below: the annotated numbers refer to their ranking (from -4 to +4 ) of the respective statement numbers. For example [S23: +3] means that this group ranked, in their ideal-type sort, statement 23 positively at position +3 on the $Q$ board).

\subsection{Factor 1-Convenience-Driven Motorists}

For Factor 1, cars represent an essential part of their lifestyle, and they could not imagine travelling in any other way. Having the possibility to go to remote natural places, often for challenging physical activities, and stop along the road to explore things, is a substantial element contributing to the enjoyment of their leisure trips [S34: +4 ; S29: +4 ; S40: +3 ; S43: +4]. The group's mobility choices are very habitualized and convenience-driven. Without ever assessing travel options besides the car [S10: +2; S6: -2 ; S36: -4 ], they believe that PT is not a feasible option in NZ [S21: +3; S3: +2], which is undoubtedly related to them not enjoying any aspect of using PT (i.e., acquaintances or time to enjoy the scenery [S30: $-2 ;$ S27: -3$]$ ). Driving, in turn, is considered practical, comfortable, independent and fun, especially in unfamiliar places [S32: +2 ; S25: -4 ; S26: -4]. Hence, while they do seek adventure, they want to be in control of the people surrounding them, as well as timing and routing. Overall, 
this group is rather reluctant to use any new infrastructures or transport options, probably preferring things to remain roughly the same [S14: 0 ; S15: -1 ; S11: +1 ; S13: 0 ]. In their overall sorting choices, this group displays a pronounced 'me-perspective', ranking personal leisure and mode choice motives highest, while largely disregarding more societal or policy-related statements.

\subsection{Factor 2-PT-Affectionate Multi-Modals}

Factor 2 contains all four car-free households, which strongly shapes the group's viewpoints on leisure mobility. When travelling, they primarily seek relaxation through beautiful landscapes and nature experiences [S40: +3 ; S39: +3 ]. Driven by curiosity, they also look for meaningful interactions with others and activities related to local culture and self-improvement [S45: +2 ; S42: +3], preferably in unknown destinations [S38: -3]. Unlike all of the other groups, they have positive associations with PT and are above-averagely familiar with PT options. To them, travels by PT add to the tourism experience through the facilitated experiences. They enjoy the possibility for new acquaintances, relaxing rides watching the scenery, and not having to focus on the road, which has an element of stress and exhaustion for them [32: $-2 ; 27:+4 ; 30:+2]$. However, they dislike the dependency on other people and on public accessibility, as well as the planning needs and limited travel options that come with New Zealand's car culture, especially in the destinations themselves [S8: +2]. Unsurprisingly, they support the idea of a more attractive and comprehensive PT network, and wish to actively challenge the prevailing car culture [S11: +2; S23: -2 ; S16: -3 ], but are divided on opinions of environmental responsibility (and implications for governmental restrictions).

\subsection{Factor 3-EV-and PT-Positive Car-Dependents}

Factor 3 displays the most unique response pattern in terms of statement placement, with a strong concern for political and infrastructural issues. Largely driven by environmental concerns, people in this group mentioned the feeling of 'guilt' related to driving [P11, P14, P20], and consider car use reductions and the change of related cultural norms as a societal and political imperative [S19: +4 ; S18: -3 ; S13: -3 ; S16: +4 ]. While still using cars for convenience and necessity reasons, their viewpoints are reflected in their travel behaviour, including electric vehicle (EV) ownership [P11] or purchase considerations [P10, P20, P22], carpooling where possible [P22], and cycling [P14]. Despite their relatively positive PT attitudes [S27: $+2 ; \mathrm{S} 37:+1]$, PT is not their transport mode of choice, especially not for trips within rural areas in NZ where they expect to experience freedom and flexibility [S21: +2 ; S7: -2$]$. They consider EVs to be the most attractive, but not yet affordable, alternative to conventional cars, and don't mind the involved planning needs, additional travel time and range limitations [S17: +4 ; S1: $-4 ;$ S24: -1 ]. Car alternatives would be an interesting option, provided that they make sense for that specific trip [S10: $-2 ; \mathrm{S} 6:-1]$.

\subsection{Factor 4-Car-Addicts for Stress Avoidance}

For Factor 4, cars represent practicality and a tool to facilitate their otherwise stressful lives. The purpose of their trips is to spend time with family [S44: +4$]$, preferably in remote natural places [S46: +3 ; S40: +2$]$, and having an uncomplicated and relaxing time while doing that [S44: $+4 ;$ S39: +4 ; S41: -3]. While they don't actually enjoy driving overly much [S32: 0], they value the convenience of taking large amounts of bulky equipment (for sports, activities, kids or pets) and not needing to plan much. The car is the choice that minimizes their travel-related stress and, as such, is the only viable and practical option for this group [S21: +2]. Consequently, they don't see much point in changing NZ's car culture [S16: +2], and value personal freedom more than environmental concerns (and the resulting policies) in this respect. Unsurprisingly, the group has no interest in or experiences with PT [S9: -4 ; S36: -3 ; S8: -1 ], accompanied by strongly negative PT attitudes [S27: -4 ; S30: -4 ], again partly justified by the forced social interaction with strangers. Despite there being EV owners in the group, they don't consider it an option for leisure trips, which is again motivated by additional planning or trip complexity and range issues [S1: $+1 ; \mathrm{S} 17:+1]$. 


\section{Qualitative Q Study Results on Factors Influencing Tourism Transport Mode Choices}

This study investigated the different notions of Christchurch residents on tourism mobility choices and their interplay with the expected tourism experience. The underlying objective was to identify different perspectives regarding the perceived benefits and motivations of personal car use, and the factors inhibiting the use of alternative, more sustainable forms of tourism mobility. The identified themes will now be presented and complemented with the qualitative interview findings (the participant numbers of each quote are annotated in squared brackets).

\subsection{The Notions of Automobility in Relation to Expected Tourism Experiences}

The results of both the $\mathrm{Q}$ study and the subsequent interviews show that the type of expected tourism experience, the activities involved and the travel company strongly influence mode choices. In line with previous research on experiential tourism expectations, the $Q$ results and the interview results identify a number of partly intersecting themes related to expected tourism experiences that relate to or motivate the tourism (auto-)mobility choices of the interviewed participants. These are: (1) the desire for private co-existence with family and friends; (2) the desire for solitude or the avoidance of unexpected encounters; (3) the wish for adventure and outdoor experiences; (4) a connection with, or an unspoiled experience of, the natural environment and sceneries by use of different senses; and (5) a desire for freedom, flexibility and control. These expectations relate to all of the stages of the tourism trip. It relates to the planning phase, where all hassles and stress ought to be avoided. It relates to the actual trip, which for some represents the start of joyful quality time with their travel groups, whereas others seek the enjoyment of natural landscape features. This enjoyment, including the palpability of the road, as well as the gaze of the surrounding landscapes, is often enhanced by the freedom to adjust the route whenever desired. Lastly, it also relates to the time spent at the destination, where automobility often enhances flexibility, privacy away from the crowds, and a sense of adventure from both the expected (including one's preferred leisure activity) and the unexpected; see also [9].

Activities, such as boating and hunting, involve large and often heavy gear, including sports equipment, toys or pet-related equipment. The statement that "the comfort of having a car like a giant suitcase is quite tempting" [P23] indicates that it may function as an extension of one's private garage, allowing for the full set of potentially pleasurable activities and the freedom to flexibly choose the most suitable one; see [20]. Nevertheless, alternatives to car travel were mentioned to enhance the experience for certain activities, namely hiking, mountain biking, kayaking (non-circular trips) and fishing (not much equipment). However, this was only mentioned by people with positive PT attitudes, who would be inclined to use them if the available offers matched their needs. For these groups, the current car dependence, despite its convenience effects, is largely caused by a lack of alternatives in terms of transport infrastructure; see also [64].

Some of the interviewed people perceive cars as a closed system where they can act and interact free of societal expectations and interactions. This expectation is line with previous findings on the desire of travellers and commuters; see the example of [65], from England, for private co-existence with family and friends rather than forced encounters with strangers [9]. Similar concerns around personal space have also been reported as a car use motive in the context of commuters. Within this theme, participants mentioned the pleasures of individual music and temperature choices, traditional family food stops, and other family rituals that have tied automobility to a pleasurable and memorable aspect of the family holiday. For this reason, the majority of people consider PT, in its reliance on consolidation effects, as the antithesis to what they look for in a leisure trip: privacy, remoteness, and freedom.

While, for certain leisure activities, the tranquillity related to remote places was a required (bird-watching, hunting) or fundamental part of the enjoyment (trekking), most people simply found it pleasurable to only be surrounded by nature, family and close friends. The desire for remoteness was somewhat perceived as a 'Kiwi right', but also represents a fundamental expectation for travellers in other places, such as peripheral Swiss mountain areas [29]. As such, not even convinced car travellers 
(factors 1 and 4) supported the expansion of transport infrastructure into remote areas because these places "need that natural limitation" [P12] and would otherwise "lose a bit of magic" [P5]; see also [29]. For most of the participants, the attachment to remote places was closely related to the need for freedom and independence in transport modes. Participants noted that "freedom is a big thing for Kiwis, they want to be able to just spontaneously go" [P10]. Partly, this is justified by the characteristics of certain leisure activities (i.e., weather-dependent sports) as well as the importance of being "in control of our own timings" [P13] that benefit from flexibility. This desire for freedom is strongly tied to the necessity of automobility [12]. It reflects the individualist traits related to car usage, allowing people to act more upon personal preferences and attitudes than societal considerations $[32,66]$.

For some, but very few, participants (mainly of group 2), automobility was associated with feelings of fear and distress. This was mentioned either in relation to the personal discomfort of driving in general or in unknown places, and also in relation to external and often unplannable traffic and weather conditions. This aspect has already been discussed by Sheller [67], who highlights the apparent paradox of cars being associated with freedom, when congestion and traffic regulations may actually be quite the opposite of freedom. Most people, however, cannot relate to this "mental bondage" of automobility because they enjoy driving and value their privacy higher than arrival times or travel speeds. For these type of travellers, the sensual enjoyment of the trip and the landscapes is much more associated with bus and train trips, where "my mind can wander, I get there in the end without having to think about it" [P4], an experience shared by travellers in previous studies [35].

\subsection{The Notions of Automobility in Relation to Urban Mobility Cultures and Sustainability Aspects}

People's leisure transport mode choices are not disconnected from their daily transport choices. They establish habits in their daily life which travel with them on leisure trips, as already mentioned previously, see [9]. Unsurprisingly, most participants commented on how Christchurch's transport network encourages car dependence. Furthermore, the oftentimes-poor PT supply in rural areas [58], especially in NZ, represents a constraint for PT use. Especially for car-free households, the existing infrastructure represents a strong limitation, and their travel plans are largely influenced by the question "Is it reachable for us?" [P6], often resulting in either dependency on other people or rental cars. As already highlighted by Fitt [4], habitus strongly affects which options are even considered viable by travellers. Some people (especially those in groups 2 and 3) don't necessarily oppose PT use; it is simply not in their mind or awareness spectrum as an actual alternative to be considered.

From the personal embeddedness in such a choice-restricting automobility culture follows a moral dilemma or attitude-behaviour gap for some more environmentally-conscious participants in groups 2 and 3, as illustrated here: "What I struggle with is picking the difference between what I actually do and what I do in my ideal reality" [P22]. Often related to the feeling of guilt, this dilemma illustrates strong social norms towards environmental protection [68,69]. As the share of environmentally conscious people in New Zealand increases [70], this effect can be expected to grow. For now, however, some study participants expressed frustration: "Somehow, the car has gained this magic status that is not allowed to be touched" [P11]. This status-quo bias is a strong decision-driver, and it affects which type of political action is societally acceptable.

While status related to transport modes was unanimously considered unimportant for travel choices within the $Q$ study, it was frequently mentioned in the qualitative interviews; for example, by stating: "I" $\mathrm{m}$ a big guy and I don't wanna look like a giant sitting inside" [Q21]. As "loser cruisers" [P7], buses were associated with people of low social classes who cannot afford a car. This is in line with Fitt's [4] study, where people mentioned the low status associated with buses, while at the same time stating that this wouldn't affect their personal choices. Buses were unanimously seen very negatively among all factors. However, diverging from the findings of Fitt's study, participants frequently justified their negative connotations by relating buses to safety concerns. Based on these concerns, people would also discourage family members from using them, highlighting the influence of peers and parents on mobility choices [36,71]. 
Train travel, on the other hand, enjoyed a better reputation across Factors 1 to 3, partly caused by people's own experiences using trains when travelling abroad. Electric vehicles (EVs) were seen as the most positive alternative to conventional cars, associated with progress and the fun of driving. Besides stigma, other constraints to using PT included the perceptions that it is slow, costly, complicated in terms of planning, and limiting in terms of destination and route choices. Especially, across Factors 1 and 4, the discomfort of having to engage in " (..) forced interactions, sitting beside somebody unknown in a bus" [P23] is a considerable limitation. Social interaction is perceived more positively among people in Factor 3 and especially Factor 2, suggesting that personality features (i.e., introversion) affect people's willingness to use PT. Hannam et al. (2014) also points out that the choice for a car is often choice against other transport modes. As highlighted by Collin-Lange and Benediktsson [72], Icelandic novice drivers frequently dismissed other travel options that they considered inferior because of perceived unreliability, lower availability or perceived safety concerns, which matches the findings of this study.

\section{Discussion and Conclusions}

\subsection{Policy and Planning Implications for Sustainable Tourism Mobility}

New Zealand's Ministry for the Environment has, as part of the country's adherence to the Kyoto Protocol and the United Nations Framework Convention on Climate Change, set both international and domestic greenhouse gas emission targets [73]. While it is on track for its 2020 targets of reducing emissions by 5 per cent compared to 1990 levels, its domestic targets are much more ambitious. As part of 2019's Climate Change Response Amendment Act, the government set into law the domestic target of being net emission free by 2050, see [74] for more details. As part of this, a NZ Emission Trading Scheme was implemented in 2008, which has also covered the transport/liquid fuel industry since 2010. Nevertheless, emissions from private transportation have risen constantly since 1990, partly caused by the increase in vehicle kilometres and supported by the lack of vehicle emissions standards.

Both in terms of infrastructure and mobility practices in New Zealand, there appears to be no default setting towards PT in general, and rail travel specifically. For New Zealand to meet its decarbonisation goals, simultaneously implemented financial, legal, infrastructural and socio-psychological (dis-)incentives are needed. Policies should also target the Christchurch transport system, given the influence of daily practices in determining tourism-related practices. Presumably, such political efforts would be challenged, given the strong societal values of the 'Convenience-driven motorists' and the 'car-addicts for stress avoidance'. For more PT-affective car users, such as the 'PT-affectionate multi-modals', it may be worth reinforcing the positive qualities of PT and the moral obligation to travel more sustainably where possible $[75,76]$.

Expanding bus travel seems impracticable, with some minor exceptions (i.e., non-circular hiking tracks). A revival and expansion of the existing train network, however, was viewed more positively, and even considered a necessity for commutes in and out of Christchurch. Personal preferences related to the values of strongly individualist societies as is NZ—-see [77] — must be taken into consideration in planning. In that context, transport operators should prioritise people's comfort and need for privacy and personal space over high vehicle occupancy when designing PT [78]. For rural travel, a train network strongly relies on flexible, most likely car-based travel options at the destination itself, although the walkability of destinations has been shown to facilitate PT use [25]. Assessing possible PT business models and respective demand patterns would be a necessary step, within which a strong emphasis should be placed on the experiential expectations of tourists in situ and en route (see Hannam, 2014). In connection to this, a combination of train and bike travels might be a worthwhile consideration which can fulfil the desire for remoteness, solitude and flexibility while also reducing long-distance transport emissions. However, given the current infrastructural settings and habitual practices, any substantial investment in passenger rail would represent a considerable change in direction for NZ transport policy. 
Besides PT, EVs were seen as an attractive and somewhat sustainable alternative to conventional petrol cars by participants (especially in Factor 3), despite people's awareness of battery production and disposal issues. The largest concern related to tourism travel by EV was believed to be the limited range of the more affordable vehicles. By increasing the awareness of existing charging infrastructure density (using existing apps, for example) and incentivizing local or national sharing schemes using long-range EVs, policy-makers could address people's range anxiety and fear of losing control.

\subsection{Conceptualising Factors Influencing Tourism Mobility Choices}

The statements of the $Q$ study, as well as the results derived from it, largely draw on the concepts of mobility cultures, the study of tourism (auto)mobilities, and findings from classical mode choice models. These three scholarly strands provide a good analytical lens for the identification of the various aspects affecting notions of automobility and related tourism mobility choices. While research (especially in positivist statistics-based fields, such as tourism and transport economics and management) often illustrates these different factors as isolated determinants [79], we would like to suggest an integrated and interconnected conceptualisation of the different dimensions affecting these choices (see Figure 3). This follows the line of argumentation of Britton [63], according to whom "the dynamics of tourism can only be fully understood with reference to its wider societal contexts". As a result, the broader societal framing must be taken into consideration when studying individual (tourism mobility) choices. The illustration in Figure 3 is based on the following arguments: first, individual agency with regards to tourism mobility is limited by the importance of structural surroundings. This refers to intrapersonal factors (i.e., family travel preferences, experiential expectations), societal and political factors (i.e., individualism and related policy debates), and the materialized infrastructure and spatial form (i.e., rural accessibility by road and PT). Second, this understanding presupposes an embedded structure of all dimensions with various feedback loops between them. Third, it reflects the hierarchical nature of the different dimensions. We are aware that this visualization, with its evenly-spaced and embedded spheres, cannot match the full complexity of reality. The order of the circles was chosen not to elect the individual as the central and most important element of our analysis, but to illustrate our understanding of the individual's limited agency and dependence on surrounding structures. We consider this a more realistic way of looking at the interconnectedness of the different spheres that shape current social tourism mobility practices.

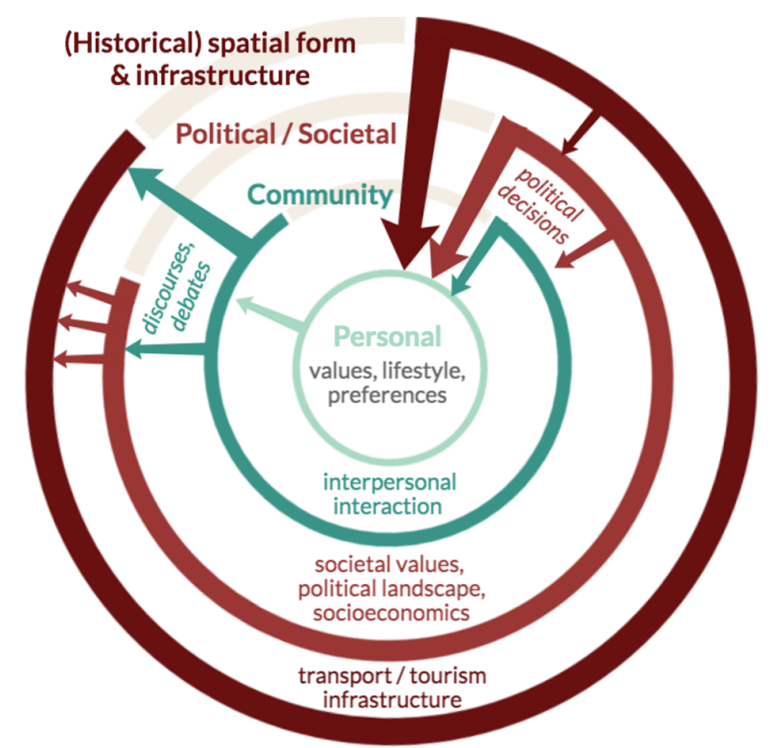

Figure 3. Relationships between the factors determining mode choices in tourism contexts. 
The analysis of all four of the identified factors and the qualitative study of the post-sorting interviews revealed several influential factors on mode choice in the tourism context. They suggest that certain instrumental factors affect mode choice considerations. While costs and time appeared as minor factors, the type of expected leisure activities and the related equipment requirements were mentioned by many respondents, especially those travelling with children.

On a more personal and interpersonal level, the experiential expectations of the tourism trip appeared as influential factors both throughout the Q-sorting and the post-sorting interviews, and they diverged between different groups. This included people's desire to find remoteness and solitude (as opposed to crowdedness and encounters with strangers) in visited places, with privacy and family time as a key aspired experience. Escaping societal expectations and feeling at home while travelling adds substantially to the enjoyment of some of the interviewed travellers, largely driving automobility developments. What is more contested is the notion of freedom, independence and fun associated with car travels. While some people perceive automobility as the definition of freedom and independence, and largely enjoy being on the road, others feel stressed by the dangers and exogenous factors (weather, traffic), perceiving the peace of mind and the lack of responsibility during train trips as pure freedom and independence, which is an insight that matches previous studies $[9,33]$.

On a societal and cultural level, social stigma around certain bus use was frequently mentioned, despite respondents denying its relevance in shaping personal mode choices. The results, however, question this notion, and assume a relationship between social stigma and personal decisions based on previous findings [4]. For electric vehicles, social stigma was much less of an inhibiting factor, since they were perceived as progressive, fun and interesting. With regards to EVs, most concerns were of a more instrumental nature, addressing range anxiety, the costs of initial investments, and uncertainties regarding future technological developments and related changes of policy objectives.

On an infrastructural and political level, the results reveal the limitations of existing transport infrastructure, both in Christchurch and rural tourism destinations. Existing structural and societal lock-in effects are accompanied by a reluctance to change, and also by a pronounced habitus towards automobility where alternatives to the private car are simply not considered, no matter the personal values, attitudes and preferences. Given the increasing environmental pressures and calls for a post-carbon future, policy-makers might experience an increasing pressure for alternative technological configurations that they ought to bring in accordance with a continued demand for comfort and convenience from the part of individual travellers, where train or coach travel are perceived as a downgrade. Finding smart and appealing solutions to this conflict of interest might be a core responsibility of policy-makers, transport planners and destination management.

Based on this conceptualisation and these results, we argue that future research should try to further bridge the gap between transport work in tourism that has often taken a largely positivist and deterministic approach, and research drawing more from social practice theories and the mobilities paradigm. Mobilities scholarship emphasises nuance, complexity and fluidity [80,81], and social practices approaches focus on the above proclaimed interconnectedness of the different elements of social life [82]. Furthermore, studies on lifestyle mobilities have highlighted that the increasing importance of physical travelling (or so-called 'corporeal mobility') in times of increasing possibilities of digital exchange has become less of a necessity, and more a matter of lifestyle choices, with choices becoming more dynamic and complex [83]. This research has found that increasing the inclusion of these perspectives would be beneficial in future explorations of mode choice for leisure trips.

\subsection{Limitations and Conclusions}

Unfortunately, the Q Method, based on its structured (and not random) sampling approach, does not aim at retrieving the exact allocations of these retrieved typologies within society; therefore, it does not allow for generalizable results across larger populations [53]. Further research using different methods will be necessary to retrieve generalizable, and therefore more policy-directed, results. Furthermore, given that all of the study participants lived in Christchurch, the variance in viewpoints 
regarding the transport infrastructure and the built environment was low. Further studies should consider applying this $Q$ set to a larger cross-cultural sample within different geographical settings in order to retrieve a broader understanding of views on the effect of the existing built environment on travel choices.

Despite this limitation, the paper makes various academic and practical contributions. Theory: the conceptual model contributes to the wider understanding of interconnected influences on notions of automobility and personal tourism mobility choices, and can help to determine the study focus of future research. Methodology: considering the limited agency of individuals within tourism mobility practices, this study contributes to the growing awareness of combining both qualitative and quantitative methods in the methodological design of future research when aiming for an understanding of travel practices and motivations. Policy: this study-when combined with similar studies-may provide Christchurch transport policy makers with a clearer picture of the complexities and experiential expectation of tourism mobilities, as well as the various psychosocial factors affecting behaviour change, which need to be addressed in order for policies to be successful and accepted. The insights from this study may also be applicable to similar cities in New Zealand, and possibly further afield. Planning: this study contributes to a wider body of literature that can help destination managers better understand the various factors along the trip chain that need consideration when wanting to increase the car-free or fossil-free accessibility of leisure destinations. While focusing mainly on the Christchurch area, these insights may still add to a wider 'toolbox' that planners can select from and adapt when seeking to make changes that are relevant to their own specific context and circumstances.

Author Contributions: Conceptualization, M.J.; Formal analysis, M.J.; Investigation, M.J.; Methodology, M.J., S.P. and H.F.; Project administration, M.J.; Supervision, S.P. and H.F.; Writing—original draft, M.J.; Writing一review and editing, M.J., S.P. and H.F. All authors have read and agreed to the published version of the manuscript.

Funding: This research received no funding beyond the travel support funding provided by the ELLS network for the Ph.D. exchange. The BOKU Vienna Open Access Publishing Fund funded the publishing of this research.

Acknowledgments: This paper was developed as part of a Ph.D. exchange program between the University of Natural Resources and Life Sciences Vienna and Lincoln University, kindly co-founded by the ELLS network. The researchers would also like to thank all pre-testers and study participants for their time and valuable insights. We also wish the anonymous reviewers for their valuable feedback.

Conflicts of Interest: The authors declare no conflict of interest.

Ethics Statement: The participants gave their written consent to the analysis and publication of the results in an anonymized manner. On these grounds, the Human Ethics Committee at Lincoln University approved this study (application number HEC 2019-88).

\section{Appendix A}

Table A1. Q statements and standardized factor scores on the extracted four-factor solution.

\begin{tabular}{|c|c|c|c|c|c|}
\hline \multirow{2}{*}{ No. } & \multirow{2}{*}{ Statement } & \multicolumn{4}{|c|}{ Score by Factor } \\
\hline & & 1 & 23 & 3 & 4 \\
\hline \multicolumn{6}{|c|}{ 3-Infrastructure } \\
\hline 1 & EVs aren't really an option for longer trips yet because the range and charging infrastructure aren't sufficient. & 0 & -1 & -4 & 1 \\
\hline 2 & I have already explored the options of travelling with an EV for myself. & -1 & -1 & 1 & 1 \\
\hline 3 & With the current train and bus infrastructure, it seems impossible to travel around NZ without a car. & 2 & 10 & 0 & 1 \\
\hline 4 & I specifically look for places that have a good amount or accommodation, food and drinking options. & -2 & 0 & -3 & -2 \\
\hline 5 & A broad visitor infrastructure, like tramping and mountain bike trails is very important for my leisure trips. & 2 & -23 & 3 & 0 \\
\hline \multicolumn{6}{|c|}{ 4-Travel Behaviour } \\
\hline 6 & I just use whatever mode of transport is most practical, so I re-assess that for every new leisure trip. & -2 & $3-$ & -1 & 3 \\
\hline 7 & Once I arrive at my holiday destination, I prefer to move around without my car. & 0 & 0 & -2 & 0 \\
\hline
\end{tabular}


Table A1. Cont.

\begin{tabular}{|c|c|c|c|c|c|}
\hline \multirow{2}{*}{ No. } & \multirow{2}{*}{ Statement } & \multicolumn{4}{|c|}{ Score by Facto } \\
\hline & & 1 & 2 & 3 & 4 \\
\hline 8 & I would love to take a relaxing train or bus to my destination, but I need a car there to visit the places I want to see. & -1 & 2 & 2 & -1 \\
\hline 9 & I have already tried traveling to rural places in NZ by train or bus. & -1 & 0 & 0 & -4 \\
\hline 10 & I don't think too much about how to travel somewhere for leisure; I just use my car wherever I go. & 2 & -4 & -2 & 1 \\
\hline \multicolumn{6}{|c|}{ 5-Policy Discourses } \\
\hline 11 & The government should invest more money in establishing a comprehensive public transport network. & 1 & 2 & 4 & -1 \\
\hline 12 & The government should invest in alternatives like EV infrastructure. & 1 & 0 & 3 & 2 \\
\hline 13 & $\mathrm{NZ}$ is too sparsely populated to build an attractive train or bus network. & 0 & -2 & -3 & 0 \\
\hline 14 & The government should invest in a more efficient road network to decrease congestion and facilitate traveling. & 0 & 0 & -1 & -1 \\
\hline \multicolumn{6}{|c|}{ 6-Problem/Environmental Awareness of Tourism Mobility } \\
\hline 15 & We should have a transport system which dissuades people from using cars, even in rural areas. & -1 & -1 & 0 & -2 \\
\hline 16 & NZ is built around cars, especially in Christchurch. Changing that wouldn't work. & 0 & -3 & -4 & 2 \\
\hline 17 & I think EVs are attractive for leisure trips, too; if you just plan it well enough. & 0 & -1 & 4 & 1 \\
\hline 18 & Everybody should just do whatever works best for them. And if they like driving, they should be able to do so. & -1 & 1 & -3 & -1 \\
\hline 19 & Everybody should feel responsible for the environment and should try to drive their cars less. & 0 & 2 & 4 & 1 \\
\hline 20 & I'm more concerned about the environment than most people and that affects how often and how I travel for leisure. & -1 & 0 & 1 & 0 \\
\hline \multicolumn{6}{|c|}{ 7-Instrumental Mode Choice Motives } \\
\hline 21 & I don't think the outdoor places that I like to visit are accessible without a car. & 3 & -2 & 2 & 2 \\
\hline 22 & I usually have a lot of bulky equipment with me that I wouldn't want to transport without a car. & 1 & -3 & 2 & 3 \\
\hline 23 & If traveling by car got significantly more expensive, I would reconsider using other transport modes for leisure trips. & -3 & -1 & 0 & -1 \\
\hline 24 & Door to door travel time plays an important role in my choice of transport mode for leisure trips. & 1 & 1 & -1 & 1 \\
\hline 25 & I find driving longer distances by car very exhausting because I need focus on the road so much. & -4 & -2 & -1 & -2 \\
\hline 26 & I dislike driving in unfamiliar places. & -4 & -4 & -3 & -2 \\
\hline 27 & Going by bus or train gives me time to read, nap or enjoy the scenery, which I enjoy a lot. & -3 & 4 & 2 & -4 \\
\hline \multicolumn{6}{|c|}{ 8-Symbolic-Affective Mode Choice Motives } \\
\hline 28 & The cars people drive reflects who they are and what they spend their leisure time with. & -1 & 1 & 0 & 0 \\
\hline 29 & $\begin{array}{l}\text { Having the freedom to stop along the way whenever I want or change my plans spontaneously is what makes } \\
\text { travelling fun. }\end{array}$ & 4 & 4 & 1 & 4 \\
\hline 30 & In the train or bus, you sometimes meet nice people. I enjoy that a lot. The car is much more lonesome. & -2 & 2 & -1 & -4 \\
\hline 31 & Going on holidays by bus or train seems a little odd to me. & -2 & -3 & -2 & 0 \\
\hline 32 & I simply love driving by car and really enjoy time on the road when going on longer trips. & 2 & -2 & -1 & 0 \\
\hline 33 & I am a dedicated follower of the four-wheel-credo. I wouldn't want to travel anywhere without my car. & -3 & -4 & -4 & -2 \\
\hline \multicolumn{6}{|c|}{ 9-Other Determinants of Leisure-Related Transport Mode Choices } \\
\hline 34 & I like to do my own thing when travelling and not depend on others or timetables. & 4 & 4 & 1 & 3 \\
\hline 35 & It annoys me sometimes that I'm so dependent on my car to get to cool places in the outdoors. & 0 & 0 & 0 & 0 \\
\hline 36 & I know exactly, which rural places I can reach by bus and transport and how to do so. & -4 & 0 & -1 & -3 \\
\hline 37 & For the type of activities I like doing, having alternatives to the car would sometimes be more practical. & -3 & 0 & 1 & -1 \\
\hline 38 & I prefer going to places that I've already been to and where I know my way around. & -2 & -3 & 0 & 0 \\
\hline \multicolumn{6}{|c|}{ 10-Travel Motives } \\
\hline 39 & When traveling, all I want is to relax and forget about the stress of every-day life. & 1 & 3 & -2 & 4 \\
\hline 40 & I am primarily looking for nature experiences and beautiful landscapes when traveling in New Zealand. & 3 & 3 & 3 & 2 \\
\hline 41 & When going on leisure trips, I need adventure and challenging experiences. & 3 & 1 & 2 & -3 \\
\hline 42 & I always want to try and learn new things to improve myself, also when I'm travelling. & 2 & 3 & -2 & -1 \\
\hline 43 & Physical activities and sports are a very important part of the leisure trips I do in New Zealand. & 4 & -1 & 3 & 2 \\
\hline 44 & The main reason to travel for me is to spend time with my family and friends. & 1 & -1 & 0 & 4 \\
\hline 45 & Travelling in New Zealand to me means experiencing and understanding the local culture. & 0 & 2 & 0 & -3 \\
\hline 46 & When I head out of Christchurch, I love to visit remote rural places where there are not many other people. & 3 & 1 & 1 & 3 \\
\hline 47 & Showing my friends or family the diversity and heritage of New Zealand is one key reason for me to travel. & 1 & 1 & 1 & -3 \\
\hline
\end{tabular}

\section{References}

1. Bell, C. 'Great Rides' on New Zealand's new national cycleway: Pursuing mobility capital. Landsc. Res. 2017, 43, 400-409. [CrossRef]

2. Tsui, K.W.H. Does a low-cost carrier lead the domestic tourism demand and growth of New Zealand? Tour. Manag. 2017, 60, 390-403. [CrossRef] [PubMed]

3. Becken, S. The Carbon Footprint of Domestic Tourism. Available online: http://hdl.handle.net/10182/1216 (accessed on 15 September 2020). 
4. Fitt, H. Habitus and the loser cruiser: How low status deters bus use in a geographically limited field. J. Transp. Geogr. 2018, 70, 228-233. [CrossRef]

5. Statistics New Zealand. Commuting Patterns in Wellington: Trends from the Census of Population and Dwellings 2006 and 2013; Statistics New Zealand: Wellington, New Zealand, 2015.

6. Becken, S.; Simmons, D.; Frampton, C. Energy use associated with different travel choices. Tour. Manag. 2003, 24, 267-277. [CrossRef]

7. Steg, L. Car use: Lust and must. Instrumental, symbolic and affective motives for car use. Transp. Res. Part A Policy Pract. 2005, 39, 147-162. [CrossRef]

8. Klinger, T.; Kenworthy, J.; Lanzendorf, M. Dimensions of urban mobility cultures-A comparison of German cities. J. Transp. Geogr. 2013, 31, 18-29. [CrossRef]

9. Hannam, K.; Butler, G.; Paris, C.M. Developments and key issues in tourism mobilities. Ann. Tour. Res. 2014, 44, 171-185. [CrossRef]

10. Hansen, A.; Nielsen, K.B. Cars, Automobility and Development in Asia: Wheels of Change; Routledge: Oxon, UK; New York, NY, USA, 2017.

11. Firnkorn, J.; Müller, M. Selling Mobility instead of Cars: New Business Strategies of Automakers and the Impact on Private Vehicle Holding. Bus. Strateg. Environ. 2012, 21, 264-280. [CrossRef]

12. Wilson, S.; Hannam, K. The frictions of slow tourism mobilities: Conceptualising campervan travel. Ann. Tour. Res. 2017, 67, 25-36. [CrossRef]

13. Page, S.J.; Ge, Y.G.; Turnbull, K.; Griffin, G.P. Transportation and Tourism: A Symbiotic Relationship? In The Sage Handbook on Tourism Studies; Jamal, T., Robinson, M., Eds.; Sage Publications: London, UK; Thousand Oaks, CA, USA; New Delhi, India; Singpore, 2009.

14. Juvan, E.; Dolnicar, S. Measuring environmentally sustainable tourist behaviour. Ann. Tour. Res. 2016, 59, 30-44. [CrossRef]

15. Rasouli, S.; Timmermans, H.J.P. Bounded Rational Choice Behavior: Applications in Transport; Emerald Group Publishing Ltd.: Bingley, UK, 2015.

16. Barr, S.; Prillwitz, J. A Smarter Choice? Exploring the Behaviour Change Agenda for Environmentally Sustainable Mobility. Environ. Plan. C Gov. Policy 2014, 32, 1-19. [CrossRef]

17. Bronner, F.; De Hoog, R. Agreement and disagreement in family vacation decision-making. Tour. Manag. 2008, 29, 967-979. [CrossRef]

18. Juvan, E.; Dolnicar, S. The attitude-behaviour gap in sustainable tourism. Ann. Tour. Res. 2014, 48, 76-95. [CrossRef]

19. Gross, S.; Grimm, B. Sustainable mode of transport choices at the destination-Public transport at German destinations. Tour. Rev. 2018, 73, 401-420. [CrossRef]

20. Le-Klähn, D.-T.; Roosen, J.; Gerike, R.; Hall, C.M. Factors affecting tourists' public transport use and areas visited at destinations. Tour. Geogr. 2015, 17, 738-757. [CrossRef]

21. LaMondia, J.; Snell, T.; Bhat, C.R. Traveler Behavior and Values Analysis in the Context of Vacation Destination and Travel Mode Choices. Transp. Res. Rec. J. Transp. Res. Board 2010, 2156, 140-149. [CrossRef]

22. Kelly, J.; Haider, W.; Williams, P.W. A Behavioral Assessment of Tourism Transportation Options for Reducing Energy Consumption and Greenhouse Gases. J. Travel Res. 2007, 45, 297-309. [CrossRef]

23. Gutiérrez, A.; Miravet, D. The determinants of tourist use of public transport at the destination. Sustainability 2016, 8, 908. [CrossRef]

24. Gutiérrez, A.; Miravet, D.; Saladié, O.; Clavé, S.A. Transport Mode Choice by Tourists Transferring from a Peripheral High-Speed Rail Station to Their Destinations: Empirical Evidence from Costa Daurada. Sustainability 2019, 11, 3200. [CrossRef]

25. Juschten, M.; Hössinger, R. Out of the city-But how and where? A mode-destination choice model for urban-rural tourism trips in Austria. Curr. Issues Tour. 2020, 1-17. [CrossRef]

26. Marrocu, E.; Paci, R. Different tourists to different destinations. Evidence from spatial interaction models. Tour. Manag. 2013, 39, 71-83. [CrossRef]

27. Davies, N.; Weston, R. Reducing car-use for leisure: Can organised walking groups switch from car travel to bus and train walks? J. Transp. Geogr. 2015, 48, 23-29. [CrossRef]

28. Karl, M. Risk and Uncertainty in Travel Decision-Making: Tourist and Destination Perspective. J. Travel Res. 2018, 57, 129-146. [CrossRef] 
29. Boller, F.; Hunziker, M.; Conedera, M.; Elsasser, H.; Krebs, P. Fascinating Remoteness: The Dilemma of Hiking Tourism Development in Peripheral Mountain Areas. Mt. Res. Dev. 2010, 30, 320-331. [CrossRef]

30. Butler, G.; Hannam, K. Flashpacking and automobility. Curr. Issues Tour. 2014, 17, 739-752. [CrossRef]

31. Haustein, S.; Nielsen, T.A.S. European mobility cultures: A survey-based cluster analysis across 28 European countries. J. Transp. Geogr. 2016, 54, 173-180. [CrossRef]

32. Cools, M.; Moons, E.; Janssens, B.; Wets, G. Shifting towards environment-friendly modes: Profiling travelers using Q-methodology. Transportation 2009, 36, 437-453. [CrossRef]

33. Beckmann, J. Automobility-A Social Problem and Theoretical Concept. Environ. Plan. D Soc. Space 2001, 19, 593-607. [CrossRef]

34. Edensor, T. Mundane mobilities, performances and spaces of tourism. Soc. Cult. Geogr. 2007, 8, $199-215$. [CrossRef]

35. Sheller, M.; Urry, J. The City and the Car. Int. J. Urban Reg. Res. 2000, 24, 737-757. [CrossRef]

36. Hopkins, D.; Stephenson, J. The replication and reduction of automobility: Findings from Aotearoa New Zealand. J. Transp. Geogr. 2016, 56, 92-101.

37. Porskamp, T.; Ergler, C.R.; Pilot, E.; Sushama, P.; Mandic, S. The importance of social capital for young People's active transport and independent mobility in rural Otago, New Zealand. Health Place 2019, 60, 102216. [CrossRef] [PubMed]

38. Ministry for the Environment. Environment New Zealand 2007; NZ Ministry for the Environment: Wellington, New Zealand, 2007; ISBN 978-0-478-30192-2.

39. Hall, M.C.; Kearsley, G. Tourism in New Zealand: An introduction; Oxford University Press: South Melbourne, Australia, 2001.

40. Thomas, J.A.; Balanovic, J.; Davison, A.; Donnell, K.O.; Frith, B.; Fairgray, D. Great Kiwi Road Trips: Enhancing New Zealand 's Tourism Industry through Better Visitor Journeys; NZ Transport Agency Research Reports: Wellington, New Zealand, 2018; ISBN 9781988561158.

41. Schänzel, H. Domestic tourism in New Zealand: The Kiwi family holiday. Pac. News 2009, 33, $24-26$.

42. Mokrý, S.; Dufek, O. Q Method and its Use for Segmentation in Tourism. Procedia Econ. Financ. 2014, 12, 445-452. [CrossRef]

43. Klinger, T.; Lanzendorf, M. Moving between mobility cultures: What affects the travel behavior of new residents? Transportation 2016, 43, 243-271.

44. Mckeown, C.B.; Thomas, D.B. Methodological Principles. In Q Methodology; SAGE Publications, Inc.: Thousand Oaks, CA, USA, 2015; pp. 1-16. [CrossRef]

45. Stergiou, D.; Airey, D. Q-methodology and tourism research. Curr. Issues Tour. 2011, 14, 311-322. [CrossRef]

46. Tan, S.-K.; Tan, S.-H.; Luh, D.B.; Kung, S.F. Understanding tourist perspectives in creative tourism. Curr. Issues Tour. 2016, 19, 981-987.

47. Brown, S.R. Political Subjectivity; Yale University Press: New Haven, CT, USA; London, UK, 1980; ISBN 0300023634.

48. Wijngaarden, V. Q method and ethnography in tourism research: Enhancing insights, comparability and reflexivity. Curr. Issues Tour. 2017, 20, 869-882.

49. Nicholas, J.B. Reliability in Q Methodology: A Case Study. In Proceedings of the Eastern Education Research Association Annual Conference, Sarasota, FL, USA, 23 February 2011.

50. Steg, L.; Vlek, C.; Slotegraaf, G. Instrumental-reasoned and symbolic-affective motives for using a motor car. Transp. Res. 2001, 4, 151-169.

51. Van Exel, N.J.A.; de Graaf, G.; Rietveld, P. Getting from A to B: Operant Approaches to Travel Decision-Making. Operant Subj. 2004, 27, 194-216. [CrossRef]

52. Imran, M.; Pearce, J. Prioritising public transport policy goals in Auckland. In Proceedings of the State of Australian Cities Conference 2015, Gold Coast, Australia, 9-11 December 2015; pp. 1-11.

53. Kougias, I.; Nikitas, A.; Thiel, C.; Szabó, S. Clean energy and transport pathways for islands: A stakeholder analysis using Q method. Transp. Res. Part D Transp. Environ. 2020, 78, 102180. [CrossRef]

54. Hermida, M.A.; Astudillo, D.; León, F. Periurban Urbanization and Travel Choice Behaviour: Problem or Solution? Iop Conf. Ser. Earth Environ. Sci. 2019, 290, 012119. [CrossRef]

55. Rajé, F. Using Q methodology to develop more perceptive insights on transport and social inclusion. Transp. Policy 2007, 14, 467-477. [CrossRef] 
56. Huang, Y.; Qu, H.; Montgomery, D. The Meanings of Destination: A Q Method Approach. J. Travel Res. 2017, 56, 793-807. [CrossRef]

57. Hutson, G.; Montgomery, D.; Caneday, L. Perceptions of outdoor recreation professionals toward place meanings in natural environments: A Q-method inquiry. J. Leis. Res. 2010, 42, 417-442. [CrossRef]

58. Le-Klähn, D.-T.; Hall, C.M. Tourist use of public transport at destinations-A review. Curr. Issues Tour. 2015, 18, 785-803. [CrossRef]

59. Watts, S.; Stenner, P. Doing Q Methodological Research: Theory, Method and Interpretation; SAGE Publications Ltd.: London, UK, 2012; ISBN 9781849204156.

60. Milakis, D.; Kroesen, M.; Van Wee, B. Implications of automated vehicles for accessibility and location choices: Evidence from an expert-based experiment. J. Transp. Geogr. 2018, 68, 142-148. [CrossRef]

61. Greater Christchurch. Travel Mode. Available online: https:/www.greaterchristchurch.org.nz/indicators/ urban/travel-modetrip-length (accessed on 30 August 2020).

62. McKeown, B.; Thomas, D. Statistical Analysis. In Q Methodology; SAGE Publications, Inc.: Thousand Oaks, CA, USA, 2011; pp. 47-64. ISBN 9781452242194.

63. Hall, C.M.; Page, S.J. The Geography of Tourism and Recreation, 4th ed.; Routledge: Oxon, UK; New York, NY, USA, 2014; ISBN 9780415833998.

64. Cairns, S.; Harmer, C.; Hopkin, J.; Skippon, S. Sociological perspectives on travel and mobilities: A review. Transp. Res. Part A Policy Pract. 2014, 63, 107-117. [CrossRef]

65. Gardner, B.; Abraham, C. What drives car use? A grounded theory analysis of commuters' reasons for driving. Transp. Res. Part F Traffic Psychol. Behav. 2007, 10, 187-200. [CrossRef]

66. Quintal, V.A.; Lee, J.; Soutar, G.N. Risk, uncertainty and the theory of planned behavior: A tourism example. Tour. Manag. 2010, 31, 797-805. [CrossRef]

67. Sheller, M. Automotive Emotions: Feeling the Car. In Automobilities; Featherstone, M., Thrift, N., Urry, J., Eds.; Sage Publications: London, UK, 2005; pp. 221-243. ISBN 9781412910897.

68. Hibbert, J.F.; Dickinson, J.E.; Gössling, S.; Curtin, S. Identity and tourism mobility: An exploration of the attitude-behaviour gap. J. Sustain. Tour. 2013, 21, 999-1016. [CrossRef]

69. Juvan, E.; Dolnicar, S. Can tourists easily choose a low carbon footprint vacation? J. Sustain. Tour. 2014, 22, 175-194. [CrossRef]

70. Ministry for the Environment. Environmental Attitudes; NZ Ministry for the Environment: Wellington, New Zealand, 2018.

71. Frater, J.; Williams, J.; Hopkins, D.; Flaherty, C.; Moore, A.B.; Kingham, S.; Kuijer, R.; Mandic, S. A tale of two New Zealand cities: Cycling to school among adolescents in Christchurch and Dunedin. Transp. Res. Part F Traffic Psychol. Behav. 2017, 49, 205-214. [CrossRef]

72. Collin-Lange, V.; Benediktsson, K. Entering the regime of automobility: Car ownership and use by novice drivers in Iceland. J. Transp. Geogr. 2011, 19, 851-858. [CrossRef]

73. Ministry of Business Innovation \& Employment. New Zealand Energy Efficiency and Conservation Strategy 2017-2022; NZ Ministry of Business Innovation \& Employment: Wellington, New Zealand, 2017.

74. Ministry for the Environment. About New Zealand's Emissions Reduction Targets. Available online: https:/www.mfe.govt.nz/climate-change/climate-change-and-government/emissions-reduction-targets/ about-our-emissions (accessed on 30 July 2020).

75. Anable, J. 'Complacent Car Addicts' or 'Aspiring Environmentalists'? Identifying travel behaviour segments using attitude theory. Transp. Policy 2005, 12, 65-78. [CrossRef]

76. Hall, C.M.; Le-Klähn, D.T.; Ram, Y. Tourism, Public Transport and Sustainable Mobility; Channel View Publications: Bristol, UK, 2017; ISBN 0261-5177.

77. Kozak, M.; Decrop, A. Handbook of Tourism Behavior: Theory and Practice; Routledge: New York, NY, USA; Abingdon, UK, 2009.

78. Jain, J. The classy coach commute. J. Transp. Geogr. 2011, 19, 1017-1022. [CrossRef]

79. Chatterton, T.; Wilson, C. The "Four Dimensions of Behaviour" framework: A tool for characterising behaviours to help design better interventions. Transp. Plan. Technol. 2014, 37, 38-61. [CrossRef]

80. Adey, P. Mobility; Routledge: Abington, UK, 2010.

81. Cresswell, T.; Merriman, P. Geographies of Mobilities: Practices, Spaces, Subjects; Ashgate Publishing: Surrey, UK; Burlington, VT, USA, 2011. 
82. Shove, E.; Pantzar, M.; Watson, M. The Dynamics of Social Practice: Everyday Life and How It Changes; Sage Publications: London, UK, 2012.

83. Cohen, S.; Duncan, T.; Thulemark, M. Lifestyle Mobilities: The Crossroads of Travel, Leisure and Migration. Mobilities 2013, 10, 155-172. [CrossRef]

(C) 2020 by the authors. Licensee MDPI, Basel, Switzerland. This article is an open access article distributed under the terms and conditions of the Creative Commons Attribution (CC BY) license (http://creativecommons.org/licenses/by/4.0/). 